\title{
Vision in schizophrenia: why it matters
}

\section{Steven Silverstein ${ }^{1 *}$, Brian P. Keane ${ }^{1}$, Randolph Blake ${ }^{2}$, Anne Giersch ${ }^{3}$, Michael Green $^{4}$ and Szabolcs Kéri ${ }^{5}$}

${ }^{1}$ Department of Psychiatry, Robert Wood Johnson Medical School, and University Behavioral Health Care, Rutgers, The State University of New Jersey, Piscataway, NJ, USA

2 Department of Psychology, Vanderbilt University, Nashville, TN, USA

${ }^{3}$ Department of Psychiatry, University of Strasbourg, Strasbourg, France

${ }^{4}$ Department of Psychiatry and Biobehavioral Sciences, University of California at Los Angeles, Los Angeles, CA, USA

${ }^{5}$ Department of Physiology, University of Szeged, Szeged, Hungary

*Correspondence: silvers1@ubhc.rutgers.edu

\section{Edited by:}

Xavier Noel, Fonds de la Recherche Scientifique - FNRS, Belgium

Reviewed by:

Wolfgang Tschacher, Universität Bern, Switzerland

Keywords: schizophrenia, vision, perception, risk, cognition, blindness, brain

Visual processing impairments are now well established in schizophrenia, including abnormalities in: contrast sensitivity (Kiss et al., 2010; Kelemen et al., 2013); excitatory and inhibitory functions such as those involved in forward and backward masking (Green et al., 2011) and surround suppression (Dakin et al., 2005); perceptual organization (Silverstein and Keane, 2011a); facial emotion recognition (Turetsky et al., 2007) and motion processing (Chen, 2011). There has been little work on color processing to date, but clinical reports indicate frequent descriptions of increased intensity of, or change in colors, in addition to changes in brightness contrast (Vollmer-Larsen et al., 2007). Of etiological relevance, visual distortions (which occur in over $60 \%$ of patients) have the highest sensitivity for conversion to a psychotic disorder among all basic symptoms (Klosterkotter et al., 2001). In addition, visual impairments in children of parents with schizophrenia predict later development of the disorder (Schiffman et al., 2006), and visual abnormalities in children in the general population are more strongly associated with the later development of schizophrenia than any other form of sensory impairment (Schubert et al., 2005). Finally, seemingly subtle visual impairments contribute to poorer real-world functioning (Rassovsky et al., 2011; Green et al., 2012). In short, visual changes (e.g., distortions, hallucinations) are common, and they have etiological, pathophysiological, and functional significance. In some cases, they can be viewed as models of impaired neural circuitry that can inform our understanding of the same connectivity problems occurring at larger scales, such as in the frontal lobe, or involving connections between brain regions (Phillips and Silverstein, 2003).

Given this, and the fact that vision is the most studied and best understood function in neuroscience, why is vision such an understudied area in schizophrenia research? (Silverstein and Keane, 2011b). Perhaps it is due to the misperception that visual findings are relatively unimportant aspects of the disorder. Much evidence, including that cited above, and included in this e-book, shows that to be untrue.
The 30 papers included in this volume make important contributions toward clarifying the mechanisms involved in visual impairments, and their relevance for schizophrenia. These are divided into sections on: (a) visual processing impairments in schizophrenia; (b) visual processing impairments in at-risk states, and the implications of data on an inverse relationship between congenital blindness and incidence of schizophrenia; and (c) broader theoretical papers. The first section begins with three papers on low-level visual impairments in schizophrenia, including findings on: (1) the interaction of color and contrast sensitivity effects (Cadenhead et al., 2013) (2) a bias toward low spatial frequency processing in face perception (Laprevote et al., 2013); and (3) the influence of comorbid PTSD on contrast sensitivity in schizophrenia. The next three papers consider inhibitory effects, including: $(4,5)$ surround suppression reductions with a variety of stimuli (Tibber et al., 2013; Yang et al., 2013); (6) the effects of change in clinical status on size contrast (Silverstein et al., 2013); (7) object-substitution masking (Wynn et al., 2013); and (8) a general approach to backwards masking impairment in schizophrenia (Herzog et al., 2013). The next four papers cover issues related to mid-level vision and perceptual organization. These include those on: (9) sex differences and clinical variables related to perceptual organization impairment in schizophrenia (Joseph et al., 2013); (10) an event-related potential marker of contour integration impairment (Butler et al., 2013); (11) neural oscillations and perceptual organization (Spencer and Ghorashi, 2014); and (12) a review of oscillatory activity and its relevance for understanding visual processing in schizophrenia. The next two papers (13,14; Christensen et al., 2013; Darke et al., 2013) address the issue of face processing abnormalities in schizophrenia. The final papers in this section cover topics related to motion processing, eye movements, temporal context processing effects and time perception. These include studies of: 15-17) biological motion perception in schizophrenia (Hastings et al., 2013; Kim et al., 2013; Spencer et al., 2013); (18-19) eye movement and scan pattern abnormalities (Delerue and Boucart, 2013; Sprenger et al., 2013); (20) visual and motor disorganization 
(Giersch et al., 2013b); (21) oscillatory markers of abnormal temporal context processing (Dias et al., 2013); and (22) the role of impaired temporal processing in visual processing abnormalities in schizophrenia (Giersch et al., 2013a).

The second section addresses issues related to risk and prevention. These include two papers on the nature of visual processing impairments in schizotypy (23,24; Bressan and Kramer, 2013; Ribolsi et al., 2013); and three papers (25-27) on the hypothesis that congenital blindness serves as a protective factor against schizophrenia, as well as the implications of these data for early cognitive-perceptual training in at-risk populations.

The third section addresses general issues. Skottun and Skoyles (2013) (28) call into question the view that the magnocellular pathway is disproportionally impaired in schizophrenia; they argue instead for a more generalized dysfunction in visual perception. The paper by Yoon et al. (2013) (29) demonstrates how studies of visual processes in schizophrenia can reveal abnormalities in general computational processes in schizophrenia. Finally, Phillips and Silverstein (2013) (30) argue that a general mechanism of context-sensitive gain control is basic to cognition and perception and is impaired in schizophrenia, which can account for many observed findings in the disorder.

Taken together, these papers provide a representative example of current work in the vision science of schizophrenia. Our hope is that this set of papers will be of use to those currently working in this field, and will stimulate others to investigate these issues. Findings addressing these questions would be of major benefit to the field of schizophrenia research, and would also inform the study of normal visual perception.

\section{REFERENCES}

Bressan, P., and Kramer, P. (2013). The relation between cognitive-perceptual schizotypal traits and the Ebbinghaus size-illusion is mediated by judgment time. Front. Psychol. 4:343. doi: 10.3389/fpsyg.2013.00343

Butler, P. D., Abeles, I. Y., Silverstein, S. M., Dias, E. C., Weiskopf, N. G., Calderone, D. J., et al. (2013). An event-related potential examination of contour integration deficits in schizophrenia. Front. Psychol. 4:132. doi: 10.3389/fpsyg.2013. 00132

Cadenhead, K. S., Dobkins, K., McGovern, J., and Shafer, K. (2013). Schizophrenia spectrum participants have reduced visual contrast sensitivity to chromatic (red/green) and luminance (light/dark) stimuli: new insights into information processing, visual channel function, and antipsychotic effects. Front. Psychol. 4:535. doi: 10.3389/fpsyg.2013.00535

Chen, Y. (2011). Abnormal visual motion processing in schizophrenia: a review of research progress. Schizophr. Bull. 37, 709-715. doi: 10.1093/schbul/ sbr020

Christensen, B. K., Spencer, J. M. Y., King, J. P., Sekuler, A. B., and Bennett, P. J. (2013). Noise as a mechanism of anomalous face processing among persons with Schizophrenia. Front. Psychol. 4:401. doi: 10.3389/fpsyg.2013.00401

Dakin, S., Carlin, P., and Hemsley, D. (2005). Weak suppression of visual context in chronic schizophrenia. Curr. Biol. 15, R822-R824. doi: 10.1016/j.cub.2005.10.015

Darke, H., Peterman, J. S., Park, S., Sundram, S., and Carter, O. (2013). Are patients with schizophrenia impaired in processing non-emotional features of human faces? Front. Psychol. 4:529. doi: 10.3389/fpsyg.2013.00529

Delerue, C., and Boucart, M. (2013). Imagined motor action and eye movements in schizophrenia. Front. Psychol. 4:426. doi: 10.3389/fpsyg.2013.00426

Dias, E. C., Bickel, S., Epstein, M. L., Sehatpour, P., and Javitt, D. C. (2013). Abnormal task modulation of oscillatory neural activity in schizophrenia. Front. Psychol. 4:540. doi: 10.3389/fpsyg.2013.00540

Giersch, A., Lalanne, L., Assche, M. V., and Elliott, M. A. (2013a). On disturbed time continuity in schizophrenia: an elementary impairment in visual perception? Front. Psychol. 4:281. doi: 10.3389/fpsyg.2013.00281
Giersch, A., Wilquin, H., Capa, R. L., and Delevoye-Turrell, Y. N. (2013b). Combined visual and motor disorganization in patients with schizophrenia. Front. Psychol. 4:620. doi: 10.3389/fpsyg.2013.00620

Green, M. F., Hellemann, G., Horan, W. P., Lee, J., and Wynn, J. K. (2012). From perception to functional outcome in schizophrenia: modeling the role of ability and motivation. Arch. Gen. Psychiatry 69, 1216-1224. doi: 10.1001/archgenpsychiatry.2012.652

Green, M. F., Lee, J., Wynn, J. K., and Mathis, K. I. (2011). Visual masking in schizophrenia: overview and theoretical implications. Schizophr. Bull. 37, 700-708. doi: 10.1093/schbul/sbr051

Hastings, C. N. M., Brittain, P. J., and ffytche, D. H. (2013). An asymmetry of translational biological motion perception in schizophrenia. Front. Psychol. 4:436. doi: 10.3389/fpsyg.2013.00436

Herzog, M. H., Roinishvili, M., Chkonia, E., and Brand, A. (2013). Schizophrenia and visual backward masking: a general deficit of target enhancement. Front. Psychol. 4:254. doi: 10.3389/fpsyg.2013.00254

Joseph, J., Bae, G., and Silverstein, S. M. (2013). Sex, symptom, and premorbid social functioning associated with perceptual organization dysfunction in schizophrenia. Front. Psychol. 4:547. doi: 10.3389/fpsyg.2013.00547

Kelemen, O., Kiss, I., Benedek, G., and Keri, S. (2013). Perceptual and cognitive effects of antipsychotics in first-episode schizophrenia: the potential impact of GABA concentration in the visual cortex. Prog. Neuropsychopharmacol. Biol. Psychiatry 47, 13-19. doi: 10.1016/j.pnpbp.2013.07.024

Kim, J., Norton, D., McBain, R., Ongur, D., and Chen, Y. (2013). Deficient biological motion perception in schizophrenia: results from a motion noise paradigm. Front. Psychol. 4:391. doi: 10.3389/fpsyg.2013.00391

Kiss, I., Fabian, A., Benedek, G., and Keri, S. (2010). When doors of perception open: visual contrast sensitivity in never-medicated, first-episode schizophrenia. J. Abnorm. Psychol. 119, 586-593. doi: 10.1037/a0019610

Klosterkotter, J., Hellmich, M., Steinmeyer, E. M., and Schultze-Lutter, F. (2001). Diagnosing schizophrenia in the initial prodromal phase. Arch. Gen. Psychiatry 58, 158-164. doi: 10.1001/archpsyc.58.2.158

Laprevote, V., Oliva, A., Ternois, A.-S., Schwan, R., Thomas, P., and Boucart, M. (2013). Low spatial frequency bias in schizophrenia is not face specific: when the integration of coarse and fine information fails. Front. Psychol. 4:248. doi: 10.3389/fpsyg.2013.00248

Phillips, W. A., and Silverstein, S. M. (2003). Convergence of biological and psychological perspectives on cognitive coordination in schizophrenia. Behav. Brain Sci. 26, 65-82; discussion: 82-137. doi: 10.1017/S0140525X03 000025

Phillips, W. A., and Silverstein, S. M. (2013). The coherent organization of mental life depends on mechanisms for context-sensitive gain-control that are impaired in schizophrenia. Front. Psychol. 4:307. doi: 10.3389/fpsyg.2013.00307

Rassovsky, Y., Horan, W. P., Lee, J., Sergi, M. J., and Green, M. F. (2011). Pathways between early visual processing and functional outcome in schizophrenia. Psychol. Med. 41, 487-497. doi: 10.1017/S0033291710001054

Ribolsi, M., Lisi, G., Di Lorenzo, G., Rociola, G., Niolu, C., and Siracusano, A. (2013). Negative correlation between leftward bias in line bisection and schizotypal features in healthy subjects. Front. Psychol. 4:846. doi: 10.3389/fpsyg.2013.00846

Schiffman, J., Maeda, J. A., Hayashi, K., Michelsen, N., Sorensen, H. J., Ekstrom, M., et al. (2006). Premorbid childhood ocular alignment abnormalities and adult schizophrenia-spectrum disorder. Schizophr. Res. 81, 253-260. doi: 10.1016/j.schres.2005.08.008

Schubert, E. W., Henriksson, K. M., and Mcneil, T. F. (2005). A prospective study of offspring of women with psychosis: visual dysfunction in early childhood predicts schizophrenia-spectrum disorders in adulthood. Acta Psychiatr. Scand. 112, 385-393. doi: 10.1111/j.1600-0447.2005.00584.x

Silverstein, S. M., and Keane, B. P. (2011a). Perceptual organization impairment in schizophrenia and associated brain mechanisms: review of research from 2005 to 2010. Schizophr. Bull. 37, 690-699. doi: 10.1093/schbul/sbr052

Silverstein, S. M., and Keane, B. P. (2011b). Vision science and schizophrenia research: toward a re-view of the disorder editors' introduction to special section. Schizophr. Bull. 37, 681-689. doi: 10.1093/schbul/sbr053

Silverstein, S. M., Keane, B. P., Wang, Y., Mikkilineni, D., Paterno, D., Papathomas, T. V., et al. (2013). Effects of short-term inpatient treatment on sensitivity to a size contrast illusion in first-episode psychosis and multiple-episode schizophrenia. Front. Psychol. 4:466. doi: 10.3389/fpsyg.2013. 00466 
Skottun, B. C., and Skoyles, J. R. (2013). Is vision in schizophrenia characterized by a generalized reduction? Front. Psychol. 4:999. doi: 10.3389/fpsyg.2013. 00999

Spencer, J. M. Y., Sekuler, A. B., Bennett, P. J., and Christensen, B. K. (2013). Contribution of coherent motion to the perception of biological motion among persons with schizophrenia. Front. Psychol. 4:507. doi: 10.3389/fpsyg.2013.00507

Spencer, K. M., and Ghorashi, S. (2014). Oscillatory dynamics of Gestalt perception in schizophrenia revisited. Front. Psychol. 5:68. doi: 10.3389/fpsyg.2014.00068

Sprenger, A., Friedrich, M., Nagel, M., Schmidt, C. S., Moritz, S., and Lencer, R. (2013). Advanced analysis of free visual exploration patterns in schizophrenia. Front. Psychol. 4:737. doi: 10.3389/fpsyg.2013.00737

Tibber, M. S., Anderson, E. J., Bobin, T., Antonova, E., Seabright, A., Wright, B., et al. (2013). Visual surround suppression in schizophrenia. Front. Psychol. 4:88. doi: 10.3389/fpsyg.2013.00088

Turetsky, B. I., Kohler, C. G., Indersmitten, T., Bhati, M. T., Charbonnier, D., and Gur, R. C. (2007). Facial emotion recognition in schizophrenia: when and why does it go awry? Schizophr. Res. 94, 253-263. doi: 10.1016/j.schres.2007. 05.001

Vollmer-Larsen, A., Handest, P., and Parnas, J. (2007). Reliability of measuring anomalous experience: the Bonn Scale for the assessment of basic symptoms. Psychopathology 40, 345-348. doi: 10.1159/000106311

Wynn, J. K., Mathis, K. I., Ford, J., Breitmeyer, B. G., and Green, M. F. (2013). Object substitution masking in schizophrenia: an event-related potential analysis. Front. Psychol. 4:30. doi: 10.3389/fpsyg.2013.00030
Yang, E., Tadin, D., Glasser, D. M., Wook Hong, S., Blake, R., and Park, S. (2013). Visual context processing in bipolar disorder: a comparison with schizophrenia. Front. Psychol. 4:569. doi: 10.3389/fpsyg.2013.00569

Yoon, J. H., Sheremata, S. L., Rokem, A., and Silver, M. A. (2013). Windows to the soul: vision science as a tool for studying biological mechanisms of information processing deficits in schizophrenia. Front. Psychol. 4:681. doi: 10.3389/fpsyg. 2013.00681

Conflict of Interest Statement: The authors declare that the research was conducted in the absence of any commercial or financial relationships that could be construed as a potential conflict of interest.

Received: 21 November 2014; accepted: 09 January 2015; published online: 05 February 2015.

Citation: Silverstein S, Keane BP, Blake R, Giersch A, Green M and Kéri S (2015) Vision in schizophrenia: why it matters. Front. Psychol. 6:41. doi: 10.3389/fpsyg. 2015.00041

This article was submitted to Psychopathology, a section of the journal Frontiers in Psychology.

Copyright (C) 2015 Silverstein, Keane, Blake, Giersch, Green and Kéri. This is an openaccess article distributed under the terms of the Creative Commons Attribution License (CC BY). The use, distribution or reproduction in other forums is permitted, provided the original author(s) or licensor are credited and that the original publication in this journal is cited, in accordance with accepted academic practice. No use, distribution or reproduction is permitted which does not comply with these terms. 